\title{
Evaluation of Phytosterols in Milk and Yogurts Used as Functional Foods in Portugal
}

\author{
David Saraiva • Maria da Conceição Castilho • \\ Maria do Rosário Martins • \\ Maria Irene Noronha da Silveira • Fernando Ramos
}

Received: 30 November 2009 / Accepted: 19 February 2010/Published online: 25 March 2010

(C) Springer Science+Business Media, LLC 2010

\begin{abstract}
The early development of cardiovascular diseases, one of the major death causes in Europe, is clearly associated with high plasmatic cholesterol levels. However, it is demonstrated that the ingestion of phytosterolsenriched milk and yogurts could reduce cholesterolemia. The purpose of the present work was to assess the commercially available phytosterols-enriched milk and yogurts. As such, the available three milk and seven yogurt presentations in Portuguese market were collected during 2008 and analyzed through gas chromatography coupled with mass detection. All the analyzed milk samples were in agreement with the proportion established by the European Commission, with $\beta$-sitosterol as the more abundant phytosterol. However, and contrarily to milk, the different yogurt manufacturers had different options in the phytosterols added to the dairy foods commercialized.
\end{abstract}

Keywords Plant Sterols · Plant Stanols · Cholesterol · Milk · Yogurt · GC-MS

D. Saraiva • M. da Conceição Castilho • M. I. N. da Silveira •

F. Ramos $(\bowtie)$

CEF - Center for Pharmaceutical Studies, Pharmacy Faculty,

University of Coimbra, Health Sciences Campus,

Azinhaga de Santa Comba,

3000-548 Coimbra, Portugal

e-mail: framos@ci.uc.pt

M. do Rosário Martins

ICAAM - Instituto de Ciências Agrárias e Ambientais

Mediterrânicas, Departamento de Química,

Universidade de Évora,

Rua Romão Ramalho, 59,

7000-671 Évora, Portugal

\section{Introduction}

According to the most recent survey, in Portugal, dairy foods represent $20 \%$ of the total daily consumption of foodstuffs, exceeding the recommended daily intake (18\%). Moreover, according to the same survey, dairy products registered in Portugal the highest growth $(>41 \%)$ in the per capita consumption. Despite its small dimension, Portugal is thus the eight European Union (EU) country in dairy foods consumption (113.3 kg inhabitant ${ }^{-1}$ year $^{-1}$ ) (INE (Instituto Nacional de Estatística) 2008).

This level of consumption renders dairy foods an importance that goes beyond the traditional associated nutritional and a very positive consumer perception. In fact, in addition to these, dairy products present a further interest as functional foods. In this context, milk and yogurts have been enriched with phytosterols, with the claim of reduction of total cholesterol and low density lipoprotein-cholesterol (LDL-C) plasmatic levels, known risk factors of cardiovascular disease (EFSA (European Food Safety Authority) 2008; Jones and Jew 2007; Moreau et al. 2002; Gonçalves et al. 2007).

Phytosterols - a generic term that refers to both plant sterols and stanols - are natural plant constituents, structurally similar to animal cholesterol, but that are not produced in humans and animals. Stanols are the saturated sterols (lacking double bonds in the sterol ring), less abundant in nature (Fig. 1) (Moreau et al. 2002). The richest natural known sources of sterols are vegetable oils and their derived products, followed by cereal grains, cereal-based products, and nuts (Piironen et al. 2000).

In addition to the mentioned blood cholesterol-lowering effect ( $2 \mathrm{~g}$ /day of phytosterols reduce LDL-cholesterol by $10 \%$ ), originally described by Pollak (Pollak 1953), phytosterols have shown the following activities in 